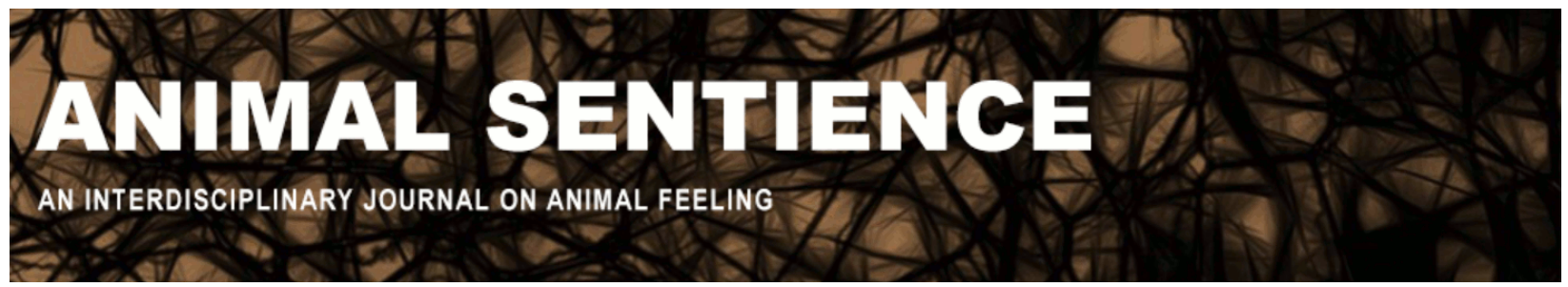

Jones, Robert C. (2016) Fish sentience and the precautionary principle. Animal Sentience 3(10)

DOI: $10.51291 / 2377-7478.1032$

Date of submission: 2015-10-01

Date of acceptance: 2015-12-11

(c)

This article has appeared in the journal Animal

Sentience, a peer-reviewed journal on animal

cognition and feeling. It has been made open access,

free for all, by WellBeing International and deposited

in the WBI Studies Repository. For more information,

please contact

wbisr-info@wellbeingintl.org.

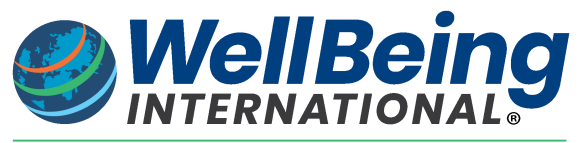

SOLUTIONS FOR PEOPLE, ANIMALS AND ENVIRONMENT 


\title{
Fish sentience and the precautionary principle
}

\author{
Commentary on Key on Fish Pain
}

\author{
Robert C. Jones \\ Department of Philosophy \\ California State University, Chico
}

\begin{abstract}
Key (2016) argues that fish do not feel pain based on neuroanatomical evidence. I argue that Key makes a number of conceptual, philosophical, and empirical errors that undermine his claim.
\end{abstract}

\begin{abstract}
Robert C. Jones rcjones@mail.csuchico.edu is Associate Professor of Philosophy at California State University. He has published numerous articles and book chapters on animal ethics, animal cognition, and food ethics, and has given over forty talks on animal ethics. http://myweb.csuchico.edu/ rcjones/
\end{abstract}

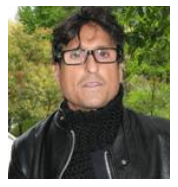

In his target article, "Why fish do not feel pain," Key (2016) makes quite a number of conceptual, philosophical, and empirical missteps along the path to his conclusion denying fish pain. In this brief commentary, I will address only three.

To begin with, Key's central premise - that human neocortical structures are required for pain - begs the question. Key's basic argument looks like this:

$P 1$. Neural structure $\mathrm{N}$ is required for mental/phenomenal state $\mathrm{M}$ in humans.

$P 2$. Thus, $N$ is a necessary condition for $M$ (that is, no $N$ entails no $M$ ).

P3. Fish lack $\mathrm{N}$.

C. Therefore, fish lack $\mathrm{M}$.

In other words, Key argues that because structure $X$ is required for mental state $M$ in humans, $X$ is a necessary condition for $M$ in fish. It's the move from (P1) to (P2) that is problematic. (Key might deny that he is making this move, but I see no other plausible way of reading his argument.) This move is problematic both empirically and philosophically. Biologically speaking, convergent evolution may implement similar functions in structures that are not homologous. For example, while it's true that the bone structure of the wings of bats is required for bats to fly, it does not follow that organisms lacking such structures, for example, bees, cannot fly. Philosophically, to say that these human structures are required for pain, again, begs the very question of whether fish are sentient. For even if those neocortical structures that Key cites are required for human pain experience, it does not follow that they are required for fish pain experience. As Colin Allen (2013, p. 36) notes, "[t]he possibility of convergent evolution at the behavioral and cognitive levels despite morphological and anatomical differences at the 
neurological level makes fish an enormously interesting testing ground for ideas about multiple realizability of cognition."

Whereas Key exhorts us to overcome our "anthropomorphic tendencies that bias interpretations of behavioral observations" and warns against jumping to "unsupported anthropomorphic conclusions" such as that fish feel pain, his central argument trades on a kind of "reverse" anthropomorphism wherein pain is a uniquely human (or mammalian) phenomenon. Key's criticism conflates two distinct and important senses of "anthropomorphism." Unnecessary anthropomorphism involves explaining behavior by attributing (what are believed to be uniquely) human traits and characteristics to beings or objects whose behavior can be better explained without such an attribution. For example, the explanation of my computer's not booting up despite my having pressed the power button is not that my computer is angry with me, but rather that there is some malfunction with the powering-up mechanism. By contrast, biocentric anthropomorphism involves the indispensable use of human terms to explain animals' phenomenal states (Bekoff 2000). It is in this second sense, not the first, that we attribute pain states to fish based on reasonable interpretations of the overwhelming behavioral evidence.

Second, Key grounds his thesis in the "bioengineering principle" that structure determines function. However, as any philosopher of biology worth her salt will tell you, this kind of reductive analysis of function is problematic and, at best, naive. Though biologists commonly correlate structure with function, it is an error to argue (as Key does) that an understanding of the neuroanatomical structure of an organism reveals that structure's function. For example, the recent discovery of a heretofore unknown structure of the human cornea (e.g., Dua's layer) certainly did not ensure the identification of its function through only structural information. Furthermore, different structures - for example, teeth and gastric acids - often carry out the same function. Key's argument relies on the mistaken assumption that pain is a functional result of one set - and only one set - of neuroanatomical structures that humans possess and fish lack. However, this type of structural-functional determinism overlooks the quite real possibility that phenomenal states like pain in fish are realizable by multiple different means.

Lastly, with regard to the ethical implications of the controversy over fish pain, Key criticizes advocates of the precautionary principle with regard to fish welfare. Advocates of the principle advise that given the lack of scientific consensus on the question of fish sentience, it is more prudent to assume that fish are indeed sentient and that this assumption should inform fish welfare policy and practice. Key warns against applying the principle in questions of fish welfare for fear of "catastrophic effects" including "inappropriate approaches to fish welfare" and negative economic impacts for the fishing industry. However, as with any decision that uses the precautionary principle, the proportionality of the risk of harm must be weighed against the cost and feasibility of a proposed action. In the case of fish, Key's conclusion that we should abandon the principle is premature. First, according to a study by the U.K. fish welfare organization Fishcount.org, about 970 to 2,700 billion fishes are caught from the wild annually. If fish are sentient (and there is good evidence that they are), then the number of sentient beings in the form of fish that are slaughtered for food annually equals at least twelve times that of the 
current human population (Mood \& Brooke 2010). If the idea of such a moral atrocity weren't enough, current world fishing trends point to a global eradication of all taxa currently fished, causing a total collapse of the fishing industry by the year 2048 (Worm et al. 2006). Surely, by any moral calculus, applying the precautionary principle regarding fish welfare is reasonable and prudential, if not obligatory.

Epistemological worries about the mental states of other-than-human animals present unique challenges to the certainty of any claims of knowing their phenomenal states. This kind of epistemological challenge is a species of a more general philosophical worry, namely, the problem of other minds, which goes something like this: Forget about whether I can ever know whether a fish feels pain: how can I ever know whether you (or any other human being) experiences pain? For all I know, you could be a philosophical zombie - a robot exhibiting all the behaviors consistent with my own pain experience, yet totally devoid of any "what-it's-like" experience.

To address the epistemological puzzle, it's not necessary to solve the mind-body problem or the problem of other minds. What we need is the ability to aggregate and synthesize our best physiological and behavioral data on the question of nonhuman animal pain, and from that, make a reasonable inference regarding the experiences and phenomenal aspects of our fellow creatures, like fish. Surely, as of the writing of this commentary, the corpus of such evidence weighs in favor of fish sentience. Yet, Key's oversights lead him too hastily, with ungrounded certainty and without sufficient warrant, to conclude that fish do not feel pain.

\section{References}

Allen, C. (2013). Fish cognition and consciousness. Journal of Agricultural and Environmental Ethics, 26(1), 25-39.

Bekoff, M. (2000). Animal emotions: exploring passionate natures. BioScience, 50(10), 861-870.

Key, B. (2016). Why fish do not feel pain. Animal Sentience 2016.003.

Mood, A., \& Brooke, P. (2010). Estimating the number of fish caught in global fishing each year. http://fishcount.org.uk

Worm, B., Barbier, E. B., Beaumont, N., Duffy, J. E., Folke, C., Halpern, B. S., Jackson, J. B. C., Lotze, H. K., Micheli, F., Palumbi, S. R., Sala, E., Selkoe, K. A., Stachowicz, J. J., \& Watson, R. (2006). Impacts of biodiversity loss on ocean ecosystem services. Science, 314(5800), 787790. 